\title{
Spatial patterns of zooplankton biomass in the northeast Pacific Ocean
}

\author{
Peter S. Rand*, Scott G. Hinch \\ Westwater Research Unit, Institute for Resources and Environment, University of British Columbia, Vancouver, \\ British Columbia V6T 1Z2, Canada
}

\begin{abstract}
We used Mantel's tests and correlograms to statistically detect and describe large-scale spatial patterns during spring and summer in zooplankton biomass in the northeast Pacific Ocean following winters of varying degrees of wind stress. During the spring of 1963, a sampling period following a winter of moderate wind stress, we found that sites separated by 1 to 100, 201 to 400 and 1101 to $1200 \mathrm{~km}$ had similar biomass levels, and that areas of high biomass occurred around the periphery of the Gulf of Alaska. We found similar results for spring data from other years following winters of high wind stress. During summers following winters of low wind stress, biomass levels were similar among sites within 1 to $100 \mathrm{~km}$ of each other, but they were generally lower than the spring values. We did not detect spatial patterns in biomass during springs following winters of low wind stress, or during summers following winters of high wind stress. Elevated winter wind stress appeared to favor the formation of discernable spatial patterns in zooplankton biomass during the subsequent spring, but the pattern did not persist into the summer. It appears that spatial patterns ('zooplankton patches' at $<400 \mathrm{~km}$ scales) may be formed by meso-scale eddies, while the similarities over larger distance intervals may be attributed to gyre currents and spring bloom dynamics.
\end{abstract}

KEY WORDS: Zooplankton-Spatial patterns - Climate - Pacific Ocean

\section{INTRODUCTION}

Most studies that have focused on statistical descriptions of the distribution of oceanic plankton have focused on small-scale spatial patterns in biomass, typically on the order of $1000 \mathrm{~m}$ or less (Haury 1976 , Mackas \& Boyd 1979, Star \& Mullin 1981). Few investigators have attempted to detect patterns at large scales $\left(10^{2}\right.$ to $\left.10^{4} \mathrm{~km}\right)$ in the world's oceans. The ability to detect spatial patterns at these larger scales and to achieve a better understanding of the mechanisms that give rise to them are critical steps in assessing and predicting changes in plankton that can lead to dramatic shifts in global fisheries production.

Spatial patterns of zooplankton are undoubtedly affected by variability in ocean currents driven by shifts in climate. Recent analyses have revealed evidence of

\footnotetext{
- Present address: Department of Zoology, North Carolina State University, Raleigh, North Carolina 27695-7617, USA. E-mail: pete_rand@ncsu.edu
}

low-frequency temporal oscillations in climate over the north Pacific Ocean (Trenberth \& Hurrell 1994). For instance, winter sea level pressure in this region had a relatively constant mean of ca $1010 \mathrm{mb}$ from 1946 to 1977, changed to ca $1007 \mathrm{mb}$ from 1977 to 1988, and then returned to ca $1010 \mathrm{mb}$ after 1988 (Trenberth \& Hurrell 1994). These climate shifts were found to influence the ocean ecosystem in fundamental ways. In particular, reductions in sea level pressure resulted in increased winter wind stress which drew relatively warm subarctic current water poleward and initiated a significant biological enrichment event through strong gyre upwelling (Brodeur et al. 1996).

One of the most striking changes in the north Pacific Ocean ecosystem associated with the reduction in sea level pressure was an increase in the abundance of zooplankton (Brodeur \& Ware 1992). Brodeur \& Ware (1992) documented an increase in summer densities of zooplankton in the Gulf of Alaska, and they suggested a shift in the distribution of zooplankton from the center of the Alaskan Gyre to the continental shelf. Their analyses, however, were limited to 1 season (15 June to 
$31 \mathrm{July)}$, and their interpretations of spatial patterns relied on subjective criteria based on visual in-spection of interpolated values.

Our main objectives for this paper are to statistically detect and describe the spatial patterns of zooplankton biomass in the northeast Pacific Ocean and to determine how biomass levels and spatial patterns change across seasons and as a function of winter wind stress.

\section{MATERIALS AND METHODS}

Zooplankton biomass was measured during summer (15 June and 31 July) during 1956 to 1963 and 1981 to 1989 (sans 1986) in the Gulf of Alaska. Sources of data are described in Brodeur \& Ware (1992). We augment their data set with additional spring sampling (1 April to 15 June) conducted during 1956 to 1963 (LeBrasseur 1965). A complete description of sampling methods is included in Brodeur \& Ware (1992) and references therein. We include only a brief summary of sampling methods here. Estimates of zooplankton biomass at each sampling station were made from hauls using NORPAC nets with a 330 to $351 \mu \mathrm{m}$ mesh. The nets were hauled from $150 \mathrm{~m}$ to the surface at $1 \mathrm{~m} \mathrm{~s}^{-1}$.

We partitioned the zooplankton biomass data into spring and summer sampling periods following winters of low, moderate and high wind stress. Wind stress relates to the intensity of alongshore winds from the south along the eastern edge of the Gulf, and from the east along the northern edge. Increases in wind stress are associated with accelerated circulation of the Alaskan Gyre, leading to increased upwelling and divergence in the center. Wind stress is reflected in values of Ekman transport, in units of 10 metric $t \mathrm{~km}^{-1}$ $\mathrm{s}^{-1}$, computed using wind data collected at $60^{\circ} \mathrm{N}$, $149^{\circ} \mathrm{W}$ (Bakun 1973, unpubl. data). The most complete spatial sampling coverage of zooplankton across the Gulf of Alaska occurred during spring sampling (4 April to 6 May) in 1963 ( $N=225$ stations). We chose to analyze this data set separately because of the large spatial extent of the sampling and the even distribution of sampling stations. Further, this sampling period followed intermediate winter wind stress (Ekman transport $=124$ ), and thus served as a baseline with which to compare results from years with more extreme wind forcing. We considered the following years (with values of Ekman transport in parentheses) as having low winter wind stress: 1957 (95), 1960 (48), 1961 (93), 1988 (72) and 1989 (53). Conversely, we considered the following years as having high winter wind stress: 1956 (156), 1959 (169), 1982 (154) and 1983 (169). Several years in the database were excluded based on limited numbers of samples. Data on zooplankton biomass were pooled among years within these 2 categories, resulting in 4 data sets with sufficient sample sizes to detect patterns (spring, low winter wind stress, $\mathrm{n}=170$; spring, high winter wind stress, $\mathrm{n}=147$; summer, low winter wind stress, $n=157$; summer, high winter wind stress, $n=121$ ). As in Brodeur \& Ware (1992), we restricted our analysis in these latter 4 data sets to sampling stations north of $48^{\circ} \mathrm{N}$. We computed means of zooplankton biomass for these data sets to reveal any marked trends across season and winter wind stress.

We constructed Euclidean distance matrices for each of the 5 zooplankton biomass data sets. Distances (i.e. differences in zooplankton biomass) were calculated among sample stations. A Euclidean distance matrix was also created for sample site locations by calculating distances between sites using their latitude and longitude coordinates. To test for a general association between geographic position and zooplankton biomass, 2-tailed Mantel's tests (Mantel 1967) were used to compare zooplankton biomass distance matrices to geographic distances [compiled BASIC program from Manly (1991) and modified by K. M. Somers, Ontario Ministry of Environment and Energy, Dorset, Ontario, Canada]. These tests enabled us to discern north-south or east-west trends in biomass. Spearman's rank correlation was used to test for the degree of concordance between the distance matrices. Consult Dietz (1983) for a further elaboration on this technique. Significance levels (set at $p=0.05$ ) for these analyses were determined using a randomization procedure involving a series of matrix permutations. The $p$-values reported herein are based on 10000 permutations for each set of matrices to achieve a stable p-value (Jackson \& Somers 1989).

To describe the presence and extent of spatial patterns in zooplankton biomass, we constructed correlograms (extension of BASIC program described above). Geographic distances between sampling stations were divided into $100 \mathrm{~km}$ intervals, and all pairs of points within each distance class were tested for association using Mantel's test. Thus, the first class included all pairs of sampling stations between 1 and $100 \mathrm{~km}$ apart, the second class included all sampling stations between 101 and $200 \mathrm{~km}$, and so on. The resulting correlation coefficients were then plotted against distance class to give a representation of the underlying spatial pattern in zooplankton biomass. Significance at each distance interval was set at $\mathrm{p}=0.05$.

\section{RESULTS AND DISCUSSION}

We detected a general association between zooplankton biomass and geographic location during spring of 1963, a year of moderate winter wind stress (overall Mantel's test, $\mathrm{p}<0.05$ ). Biomass was relatively 


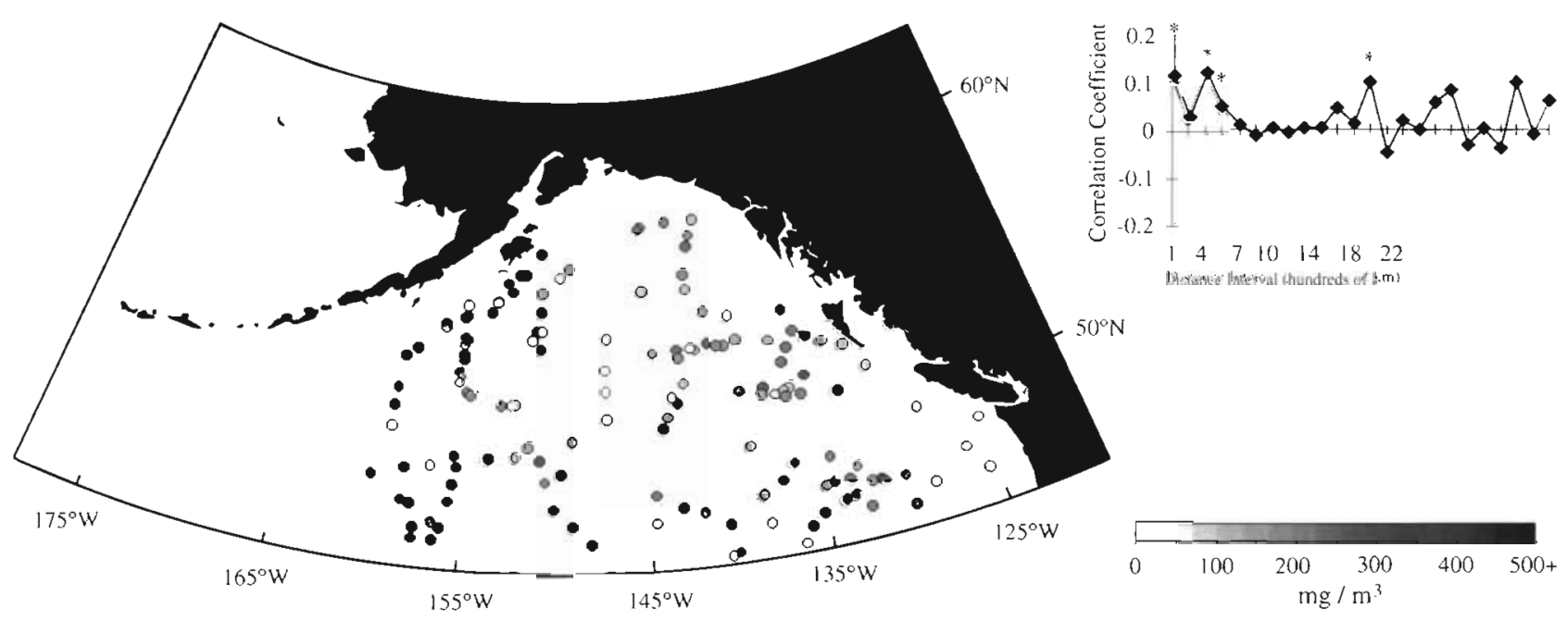

Fig. 1. Northeast Pacific Ocean showing locations of the net zooplankton sampling stations. Zooplankton biomass during 4 April to 6 May 1963 is shown at each station using a gray scale. The correlogram reports the results of the statistical tests for spatial patterns. Asterisks appearing over values for correlation coefficients indicate significance at $\mathrm{p}=0.05$

high in the extreme western and eastern portions of the study area, but markedly lower in the central region (Fig. 1). The correlogram indicated significant positive correlations at distance intervals of 1 to 100 , 201 to 400 and 1101 to $1200 \mathrm{~km}$ (Fig. 1).

Changes in biomass from low to high winter wind stress were very dramatic during the spring (Fig. 2a, b). We found a 2 -fold increase in zooplankton biomass accompanying the increases in winter wind stress (spring, low winter wind, $98 \mathrm{mg} \mathrm{m}^{-3}$; spring, high winter wind, $203 \mathrm{mg} \mathrm{m}^{-3}$ ). We detected no significant geographic spatial patterns in either spring data set (Mantel's test, $p>0.05$ ), although spring biomass collected following winters of high wind stress was generally greater in the western and central regions of our study area (Mantel's test, $\mathrm{p}=0.07$; Fig, 2b). The correlogram for spring biomass following a winter of low wind stress was relatively flat, with no significant correlation at any distance interval. The correlogram representing conditions following a winter of high wind stress events had a more jagged appearance, with significant correlations occurring at distance intervals of 1 to 100 , 301 to 400 and 1101 to $1200 \mathrm{~km}$. The geographic distribution of biomass and the spatial patterns reflected in the correlogram following a winter of high wind stress were similar to those observed during the spring of 1963 (described above), except that values were higher in the center of the gyre.

Zooplankton biomass was higher in summer following a winter of high wind stress than one of low wind stress (Fig. 2C, d), although the difference (ca 50\% increase) was less pronounced than that observed during spring (summer, low winter wind stress, $107 \mathrm{mg}$ $\mathrm{m}^{-3}$; summer, high winter wind stress, $157 \mathrm{mg} \mathrm{m}^{-3}$ ).
Summer biomass was greatest in the western region of the study area following a winter of low wind stress (Mantel's test, $p=<0.01$; Fig, 2c), but there were no obvious spatial patterns in the distribution of summer biomass following a winter of high wind stress (Mantel's test, $p=0.12$; Fig. $2 \mathrm{~d}$ ). The correlogram generated from the summer data following low winter wind stress revealed a significant positive correlation at the distance interval of 1 to $100 \mathrm{~km}$. The correlogram for summer data collected following high winter wind stress revealed no spatial patterns (Fig, 2d), suggesting a random distribution of zooplankton biomass throughout the Gulf of Alaska.

It appears that following winters in which wind stress is high regular spatial patterns of zooplankton biomass occur, but not during the summer. The spatial patterns that we detected appear to fall into either meso- $(<400 \mathrm{~km})$ or gyre- $(>1000 \mathrm{~km})$ scale structures. The patterns we detected are most likely caused by hydrodynamic features, coupled with biological production mechanisms influencing reproduction in zooplankton (Mackas et al. 1985). We speculate that the patterns in zooplankton biomass noted at meso-scales are structures (e.g. 'patches' or rings) resulting from physical processes occurring within eddies. Roden (1977) examined meso-scale physical structures over much of the mid-latitude north Pacific Ocean and found eddies typically 150 to $200 \mathrm{~km}$ in diameter, which corresponds to the distance intervals at which we detected associations in our zooplankton data. These meso-scale physical disturbances have been noted to be prevalent in the western and central north Pacific, but relatively rare in the eastern north Pacific (Kenyon 1978) where our data were collected. The 

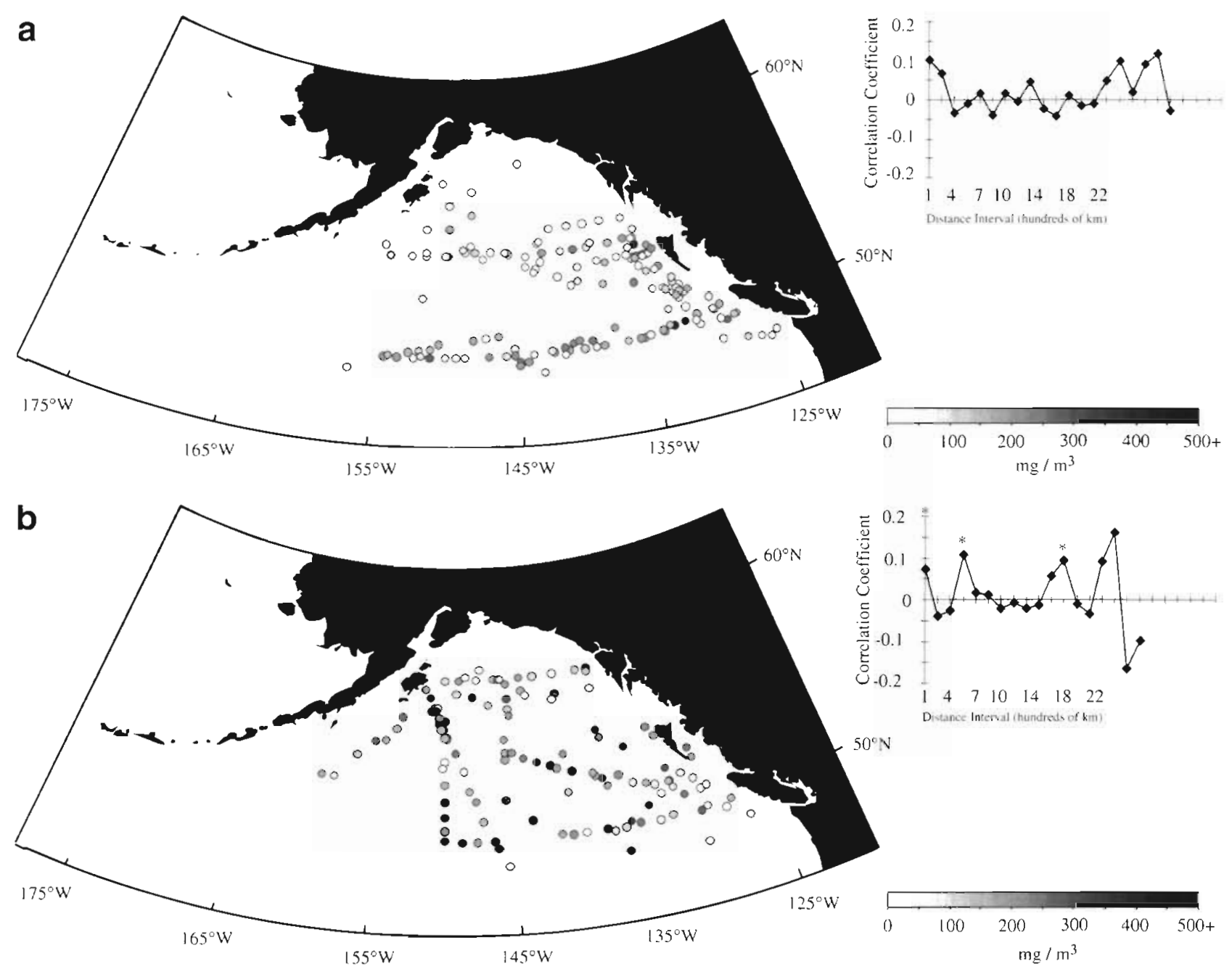

Fig. 2 (above and facing page). Zooplankton biomass data collected during the spring sampling period following (a) low and (b) high winter wind stress, and during the summer following (c) low and (d) high winter wind stress. All else as for Fig. 1

transects where these physical observation were made, however, were conducted at latitudes south of our study region $\left(28^{\circ}\right.$ and $\left.35^{\circ} \mathrm{N}\right)$. Regions or 'patches' of high biomass appeared to be either in areas adjacent to coastal upwelling zones (e.g. in the northwest part of our study region), or in areas near the convergence of 2 offshore current fields (e.g. the Alaskan Stream running parallel to the Aleutian Islands and the Subarctic Current straddling the $45^{\circ} \mathrm{N}$ line). These regions are know to propagate meso-scale disturbances that can influence biological properties of entrained water masses, which may result in the formation of meso-scale 'patches' of zooplankton.

The patterns we detected at gyre-scale distance intervals (ca $1000 \mathrm{~km}$ ) may be related to physical factors involved in spring bloom dynamics. Parsons et al. (1966), through visual inspection of the plotted data, noted a crescent-shaped pattern of high zooplankton biomass extending over $1000 \mathrm{~km}$ based on the
April-May 1963 data presented here. The statistical tests we applied in this study provide more rigorous support for the existence of this feature in the Gulf of Alaska. Parsons et al. (1966) argued that this phenomenon was driven by high rates of primary productivity around the periphery of the gyre resulting from patterns in the critical depth and the depth of the mixed layer. Our more extensive analysis allowed us to detect a similar ring pattern of zooplankton biomass during springs following winters of high, but not low, wind stress. These results suggest the presence of this biological feature may be climate dependent.

Our analysis of changes in zooplankton biomass under different levels of winter wind stress gives results which are generally consistent with the conclusions drawn by Brodeur \& Ware (1992) in their analysis of summer zooplankton distributions under low and high winter winds. However, our analysis of spring data suggest the effect of winter wind stress that char- 

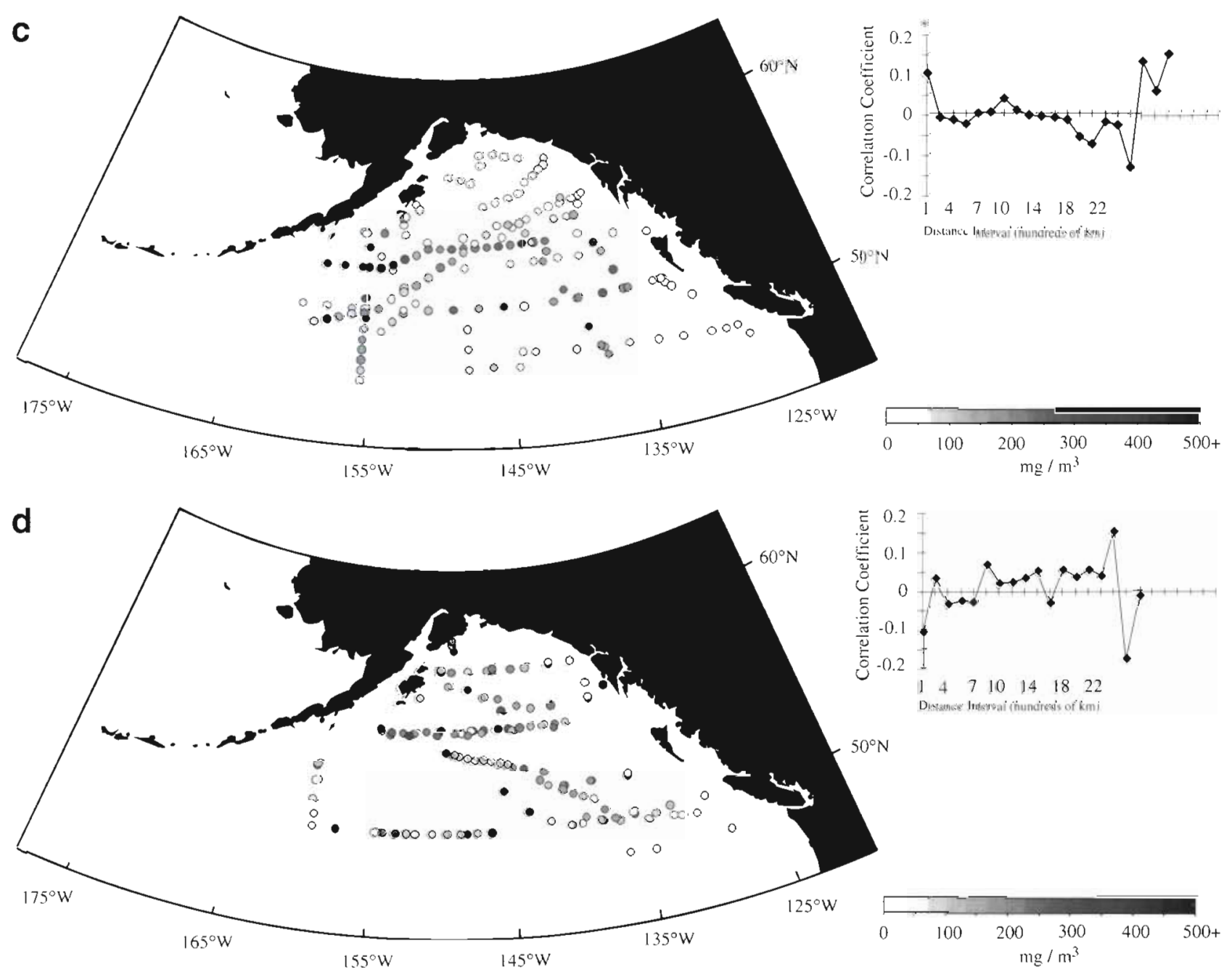

acterized the recent climate regime shift (during 1977 to 1988) may have had an even more pronounced effect on biological production than originally indicated by Brodeur \& Ware (1992), who based their conclusions on data collected only during June and July. Indeed, while our estimated summer zooplankton biomass increased by approximately $50 \%$, spring biomass more than doubled. The period of highest biomass of zooplankton measured at Ocean Station ' $\mathrm{P}$ ' $\left(50^{\circ} \mathrm{N}\right.$, $145^{\circ} \mathrm{W}$ ) from the surface to $150 \mathrm{~m}$ depth occurs in late May to early June (McAllister 1961), which suggests that, if a biological enrichment event occurs, it should be most pronounced during the spring.

As a result of pooling data among years, our analyses are insufficient to fully address whether the spatial patterns we report are geographically fixed from year to year. The similarity in the overall biomass and spatial patterns detected in the data set that included only within-year samples (spring of 1963) and the data sets that pooled among-year samples (spring, high winter wind stress) suggest that any interaction between year and winter wind stress, which could confound our interpretation, was not pronounced. This question becomes quite critical when investigators infer seasonal and interannual changes in the plankton community in the northeast Pacific Ocean based on sampling at only 1 location (e.g. Ocean Station 'P'). A plankton sampling program that includes a more evenly distributed sampling grid of stations would help address this issue more rigorously.

Acknowledgements. We are grateful to Andrew Lotto for digitizing the data and Pier van Dishoeck for helping to create the figures. We thank Keith Somers (Ontario Ministry of Natural Resources, Canada) for providing the code to conduct the spatial analyses. We also acknowledge the help of Ric Brodeur (National Marine Fisheries Service, Seattle, WA, USA) for providing data, advice and assistance. P.S.R. was supported through an NSERC strategic grant to $M$. Healey, C. Walters, and P. LeBlond and an NSERC Research Grant to S.G.H. 


\section{IITERATURE CITED}

Bakun A (1973) Coastal upwelling indices, west coast of North America, 1946-71. NOAA Tech Rep NMFS (Natl Mar Fish Serv) SSRF (Spec Sci Rep Fish) 671:103

Brodeur RD, Frost BW, Hare SR, Francis RC, Ingraham WJ (1996) Interannual variations in zooplankton biomass in the Gulf of Alaska, and covariation with California current zooplankton biomass. CALCOFI (Calif Coop Oceanic Fish Invest) Rep 37:80-99

Brodeur RD, Ware DM (1992) Long-term variability in zooplankton biomass in the subarctic Pacific Ocean. Fish Oceanogr 1:32-38

Dietz EJ (1983) Permutation test for association between two distance matrices. Syst Zool 32:21-26

Haury LR (1976) A comparison of zooplankton patterns in the California Current and North Pacific Central Gyre. Mar Biol 37:159-167

Jackson DA, Somers KM (1989) Are probability estimates from the permutation model of Mantel's test stable? Can J Zool 67:766-769

Kenyon KE (1978) The surface layer of the eastern North Pacific in winter. J Geophys Res 83:6115-6122

LeBrasseur RJ (1965) Biomass atlas of net zooplankton in the

Editorial responsibility: Otto Kinne (Editor),

Oldendorf/Luhe, Germany northeastern Pacific Ocean, 1956-1964. Fish Res Bd Can Manuscr Rep Ser (Oceanogr Limnol) 201

Mackas DL, Boyd CM (1979) Spectral analysis of zooplankton spatial heterogeneity. Science 204:62-64

Mackas DL, Denman KL, Abbott MR (1985) Plankton patchiness: biology in the physical vernacular. Bull Mar Sci $37(2): 652-674$

Manly BFJ (1991) Randomization and Monte Carlo methods in biology. Chapman-Hall, New York

Mantel N (1967) The detection of disease clustering and a generalized regression approach. Cancer Res 27:209-220

McAllister CD (1961) Zooplankton studies at Ocean Weather Station $P$ in the northeast Pacific Ocean. J Fish Res Bd Can 18(1): $1-29$

Parsons TR, Giovando LF, LeBrasseur RJ (1966) The advent of the spring bloom in the eastem subarctic Pacific Ocean. J Fish Res Bd Can 23(4):539-546

Roden Gl (1977) On long-wave disturbances of dynamic height in the North Pacific. J Phys Oceanogr 7:41-49

Star JL, Mullin MM (1981) Zooplankton assemblages in three areas of the North Pacific as revealed by continuous horizontal transects. Deep-Sea Res 28:1303-1322

Trenberth KE, Hurrell JW (1994) Decadal atmosphere-ocean variations in the Pacific. Clim Dyn 9:303-319

Submitted: January 26, 1998; Accepted: June 2, 1998 Proofs received from author(s): September 8,1998 